or 9 inches high. This gradual plane often effected a cure without any other interference.

Dr. AUST-LAWREnce observed that in some cases the ordinary symptoms of retroflexed gravid uterus might be present, and yet the pelvic tumour was not the body of the uterus, but a retro-uterine blood tumour. He mentioned cases in which this tumour was an extra-uterine pregnancy. He recommended that the bladder should be emptied, and the patient put in Sims's position or knee-elbow, if necessary, and attempts made to replace the uterus without an anæs thetic; if this could not be done at once, the patient should be kept in bed, and the attempt renewed in a few days. The main danger lay in the bladder; it was therefore necessary to keep it relieved, and some days might be allowed to elapse before the replacement. Dr. Aust-Lawrence mentioned one case that was allowed to go on for six months, when he replaced the uterus; and also one case that went on to full term and died.

\section{SECTION OF PSYCHOLOGY.}

\section{T. W. McDowall, M.D., President.}

INSANITY FROM THE ABUSE OF INDIAN HEMP Dr. Thomas Ireland (Government Medical Officer, British Guiana) said that the excessive use of Indian hemp, or cannabis indica, had long been recognised in Eastern countries as one of the most common vices, and as a very prolific cause of insanity. It had been introduced into British Guiana and the West Indies by the East Indian coolie immigrant. The vice was almost entirely confined to the male sex and to Hindus, Indian Mahomedans being rarely addicted to it. In British Guiana, fully 30 per cent. of the coolie patients admitted into the Berbice Lunatic Asylum showed a history of having been habitual smokers of the drug. Dr. Ireland then proceeded to describe the different forms in which Indian hemp was prepared and used, bhang being the cheapest and commonest, producing quiet, pleasant delirium and stupor. Churrus, which was the dried sticky resin, caused excitement attended with violence. The drug was also used in the form of a sweetmeat called majoom, and smoked as ganja, made from the dried flower tops, the latter preparation being the one generally employed by the coolies in British Guiana and the West Indies. After describing the different stages of incipient mental disorder, and the course of the various types of insanity due to the excessive use of Indian hemp, with their prognosis and treatment, Dr. Ireland remarked that as yet no special pathological change had been observed in such cases, except the common occurrence of asthma in ganja smokers. He illustrated his remarks with a clinical account of three typical cases of the extreme forms of insanity, the first being one of acute mania with homicidal impulse; the second acute melancholia, with attempted suicide; and the third one of chronic dementia.

Dr. Murray Lindsay was greatly impressed by one fact mentioned in the paper, namely that the use of Indian hemp was confined to the male sex, and he desired some explanation on this point, because it was well known that in the United Kingdom the alcohol and opium habits were by no means confined to one sex.

Mr. Peeke Richards asked Dr. Ireland whether any legislative action had been attempted to prevent the injurious results described.

Dr. Tuke asked Dr. Ireland whether, in his experience, the condition which was called " running amok" by the Malays was caused by cannabis indica. Dr. Gismore Ellis, who resided in the Malay peninsula, in a recent paper on this peculiar condition, stated that he did not find that it was due to Indian hemp or any similar drug.

Dr. Campbell Clark suggested that the Section might express an opinion on the use of the drug. Dr. Clark had found it useful in utero-ovarian cases, especially at the climacteric, when it was often a reliable sedative.

Dr. URQUHART referred to a case of adolescent melancholia, with some degree of stupor, who on admission was found to have in his pocket a quantity of powdered vegetable matter which could not be identified. The patient recovered in a short time, and stated that he had been smoking cannabis indica in Algiers before his mental symptoms occurred. Although this patient was highly neurotic, it might be that the insanity was caused in some measure by the drug.

Dr. R. H. Nootr remarked on the close resemblance between the effects of the abuse of Indian hemp, and the effects of the abuse of alcohol.

Dr. Alex. Patton mentioned that he had treated two very severe cases of traumatic tetanus with the steady use of 1 drachm of the tincture of Indian hemp, repeated as often as the spasms recurred or increased in violence. Both cases recovered; one in three weeks, the other in a shorter period.

Dr. T. InELAND, after thanking the meeting for the very kind manner in which his paper had been received, said, in reply to Dr. Lindsay, that the reason why the abuse of Indian hemp was confined to the male sex amongst Hindus was that the female sex did not get the chance to use it. The male member of a Hindu family was the head of the house, and enforced his position as such with a big bamboo stick on the female members. In reply to Mr. Richards, he said that stringent laws had been made in Trinidad with the purpose of preventing the coolies getting Indian hemp, but as yet nothing had been done in that direction in Guiana. It was generally believed that persons who made homicidal attacks on others (running amok) were at the time under the influence of Indian hemp. The irresistible impulse to kill was one of the characteristic symptoms of intoxication from this drug, and might exist without the existence of any delusions or hallucinations to account for it. It was difficult to gain a correct knowledge of the mental state of such persons unless they remained insane. He agreed as to the value of Indian hemp as a sedative and soporific in some other forms of insanity.

\section{NOTE ON THE BACTERIOLOGY OF CHOLERA NOSTRAS.}

Br E. J. McWEENEY, M.A., M.D.,

Professor of Pathology and Bacteriology in the Catholic University of Ireland; Pathologist to the Mater Misericordia Hospital, Dublin.

In the beginning of August I received from Dr. Finegan, Medical Superintendent of the Asylum, Mullingar, a specimen of stools from a patient in the institution, with the request that I should examine it bacteriologically and ascertain if the case were one of Asiatic cholera. The patient had been suddenly attacked with vomiting, severe diarrhœa, and cramps chiefly in the calves of the legs, and had become collapsed, the temperature falling to $97^{\circ}$. The condition of the patient had become critical in the extreme, and was highly suggestive of the algid collapse of Asiatic cholera.

I at once proceeded to examine the dejecta, and was struck by their typical rice water character; small whitish translucent flocculi could be seen floating in the turbid liquid portion. The odour was peculiar, like sour milk, and not in the least fæcal in character. Cover glass preparations of a flocculus stained with Loeffler's blue showed numerous bacilli of various lengths, mostly short and "plump." Dumb-bell forms were frequent, and many slightly curved forms were met with, scarcely distinguishable from comma bacilli save by the absence of constancy in the curve, the neighbouring organisms being mostly straight.

Cultivations were made in three ways: A. On ordinary faintly alkaline nutrient gelatine; в. On nutrient gelatine that had been rendered strongly alkaline (in accordance with the suggestion of Dahmen), ${ }^{1}$ so as to accord better with the known preference of Koch's vibrio for an alkaline substratum; c. A flocculus was held in sterile forceps, rinsed in three successive glasses of sterile water, and introduced into a test tube containing 15 c.c. of sterile 1 per cent. solution of peptone in 0.5 per cent. solution of common salt. Several such tubes were prepared.

Plates were poured of $\mathbf{A}$ and $\mathbf{B}$ into Petri's double dishes, and placed in the low-temperature incubator regulated for $22^{\circ} \mathrm{C}$. The tubes described under $\mathrm{c}$ were incubated at $37^{\circ} \mathrm{C}$ in a slanting position. Within forty-eight hours the colonies on the gelatine plates were fully developed and ready for determination. On none of the plates was there a single 
liquefying colony. All were similar, and obviously belonged to the same species, which was readily determined to be bacillus coli communis (Escherich). The Schottelius tubes contained pure cultivations of the same organism, as was readily ascertained by plating out. Two c.cm. of the liquid in one of these tubes, intraperitoneally injected, killed a rabbit in thirty-six hours. Post mortem, acute peritonitis, with slight turbid effusion containing, no doubt, the bacilli in a state of exalted virulence; but the matter was not pursued further.

There can thus be no doubt that the case was not one of Asiatic cholera, but of choleraic diarrhœa, due to the micro-organism which existed in pure cultivation in the evacuations. It is highly interesting to note that this observation agrees exactly with that of Lesage and Macaigne, ${ }^{2}$ who found that the severer the symptoms the more undisputed is the possession of the bowel by this virulent variety of Escherich's bacillus, to which Gilbert and Girode give the name of B. coli "cholerigène." Hueppe ${ }^{3}$ seems to have been the first to point out organisms of the typhoid group as the cause of many cases of cholera nostras.

Turning now to the points of interest presented by this case, I shall mention, first of all, one that will be of interest chiefly to bacteriologists. It is of course well known that the reaction, and no doubt other less easily ascertained characters of the substratum, exercise a marked effect upon the appearance of the culture. This fact was strikingly exemplified by the difference that existed between the colonies of $B$. coli on the plates (A) above and those on the plates (B). In the former case they were bluish-white opaque with wavy margins, and of equal thickness, or nearly so, from centre to margin; in the latter the colony was bordered round by an extremely delicate widespreading transparent veil-like border, which extended round it, following its every bend and angle, and from 1 to $2 \mathrm{~mm}$. broad. This border was constant round the superficial colonies on the highly-alkaline plates, and had an observer met with it in describing the organism for the first time he would have been inelined to insist upon this feature as characteristic. And yet it was consistently absent from the colonies on the faintly-alkaline medium.

Another point of interest is the behaviour of the Schottelius tubes. There was no semblance of membrane or zooglœea at any time; only a diffuse turbidity and abundant precipitate of organisms as a flocculent deposit. There is, of course, nothing new in this observation; but at a time like the present, when cholera has set foot in England, it is as well that the behaviour towards the cholera tests of organisms which are likely to occur in suspected dejecta should be confirmed by experiment and made known as widely as possible.

The same remark applies to the last observation I shall make, namely, as regards the result of the microscopic examination of the flocculi. Curved forms, indistinguishable from Koch's vibrio, were quite numerous. Yet the crucial test of culture showed that none were present. Of course the skilled observer would have been struck by the absence of the arrangement in rows, described as typical by Koch and by the transitional form to the straight plump rods and dumb-bell forms. But even a careful microscopist, unaccustomed to bacterial work, might have been tempted to look upon the curved objects as comma bacilli.

By active treatment Dr. Finegan succeeded in bringing his patient safely through the collapse, and, after four days severe illness, she recovered.

2 sem. Méd., 1892, p. 40

Berl. klin. Woch., 1887, p. 591.

MEDICAL STORES:IN INDIA.-We are glad to see that the Government of Madras has taken alsensible view of the question of the supply of drug to civil hospitals and dispensaries. It appears there was a rule limiting the home indents for medicines to the average amount expended durin the three previous years, so that when there was an increase in the number of civil dispensaries or hospitals the supply of drugs ran short. This has now been altered, and when a reasonable explanation can be given 'for exceeding the three years' average the civil surgeon-general is authorised to indent for what may be necessary. This is only common sense, as when hospitals and dispensaries are estahlished they would be useless without an adequate supply of medicines.

\section{REVIEW S.}

The Englisil Babi in India. By Mrs. Howard Kingscote. With a preface by Surgeon-Captain R. H. FirTh, Army Medical Service. London: J. and A. Churchill. 1893. (Crown 8vo., pp. 194, 2s. 6d.)

THIs little book is intended not so much for the educated women as for their sisters in bungalow and barrack, to whom a small and simple book containing sensible and practical advice is of great value. There are many excellent books written for the help and instruction of the wife and mother, but they deal with these matters from an English point of view, and frequently contain statements and advice that are not applicable to the circumstances of life in India.

A careful perusal of Mrs. KINGscote's book shows at once its strength and its weakness. It is strong in that it is evidently the outcome of the personal experience of a sensible and thoughtful woman. It is weak in that she has no adequate knowledge of medical facts; that she confounds a part of India with the whole, and frequently uses expressions which are unintelligible save to those who have lived where they are used. Thus, on page 173 we are told some remedy is to be administered "in doses of from one to two mashas." This word is unintelligible to many who have lived long in India.

The second chapter deals very wisely with the question of clothing a baby in India, but in the third there are a few points which appear unsound. For instance, the expectant mother is advised not to engage a nurse recommended by her doctor, because he "can only judge of her capacity for work, and not whether she is clean and pleasant in the lying-in room, bright, willing, etc. She should, therefore, have one of whom she has heard something through some friend." It is to be remembered, however, that the safety and comfort of the mother and infant are the physician's responsibility, while much of the after-care necessarily devolves on the nurse. Unless the medical attendant can rely on her adequate knowledge and absolute conscientiousness, his anxiety and work are very greatly increased. He usually knows more about the nurse's personal character than can any friend outside the profession, and seldom employs any woman whose conduct in former cases has not been in all respects' ${ }^{\text {satis- }}$ factory. It is also to be remembered that a nurse who suits one patient well may not be so acceptable to another; what one patient likes and applauds as "carefulness," irritates another, who looks on the same amount of attention as "fussiness."

Again, Mrs. Kingscote tells us that " another great mistake made during the lying-in month in India is that of washing and tidying the patient too early, and a medical man should be asked not to visit before 9 or 10." Surely this is a mistake. How can a nurse dictate to the doctor when the visit is to be paid? Distances are great in India, and should two or three lying-in patients live in diffcrent parts of the town, it is not possible to see them all and fit in the usual morning round unless a start is made in the early hours of the day. No reasonable attendant will be displeased if the washing, etc., be not finished at the time the visit is paid.

The book is marred by a want of method; for instance, Chapter III begins with the choice of a nurse, but this is immediately interrupted by some details as to the management of the child-after a few lines of this comes the advice to which we have objected as to the friends' recommendation being preferred to the doctor's-to this succeed a list of baby clothes, and some excellent advice as to attitude of mind for the expectant mother, and then again the authoress returns to the qualities requisite in a nurse. On the next page is a well considered dietary for the mother; all good except that the use of wine and "home brewed ale" (we wonder where that is to be got on the plains of India) is too generally sanctioned. The nurse then has another turn, and is cautioned as to personal cleanliness, smartness, etc. It is a pity so to mix the subjects; the women for whose use the little book is written want advice clearly stated, ready for immediate reference.

We are very glad to note that the authoress recommends the use of the douche at least twice a day until all discharge ceases, but it is to be regretted that no mention is made of 